\title{
Lógica do Mercado na Rede Pública Municipal de
}

\section{Manaus/AM}

\author{
Rudervania da Silva Lima Aranha \\ Selma Suely Baçal de Oliveira \\ Universidade Federal do Amazonas (UFAM), Manaus/AM - Brasil
}

\section{Resumo}

Este artigo objetiva discutir a materialização das políticas neoliberais por meio da implementação do Projeto de Expansão e Melhoria Educacional da Rede Pública de Manaus (PROEMEM), na rede pública municipal de Manaus/AM. O estudo é decorrente de resultados obtidos com a conclusão de dissertação defendida junto ao Programa de Pós-Graduação em Educação da Universidade Federal do Amazonas, cujo objetivo foi analisar a lógica do mercado na rede de ensino no município de Manaus/AM. Questionam-se as implicações desse processo para a educação nesse município. Trata-se de pesquisa de caráter qualitativo, a partir de uma revisão de literatura, levantamento e análise de documentos primários, no período de 2013 a 2017. Os resultados apontam que existe um inegável movimento em prol de viabilizar a expansão de instituições privadas no setor educacional, que encontram novos nichos de exploração econômica, de maneira a permitir a apropriação privada do bem público, sem, contudo, gerar efetivamente a melhoria da rede escolar pública. A aceitação dessa lógica promove mudanças nas concepções de escola pública, com a incorporação de instituições privadas na rede municipal de ensino.

Palavras-chave: Educação Pública. Mercado Educacional. Setor Privado.

\section{The Market Logic in Manaus/AM Municipal Public Network}

\section{Abstract}

This article aims to discuss the materialization of neoliberal policies through the implementation of the Educational Expansion and Improvement Project of the Public Network of Manaus (PROEMEM), in the municipal public network of Manaus/AM. This study results from the data obtained with the conclusion of a dissertation defended in the Graduate Program in Education at the Federal University of Amazonas, with the objective of analyzing the logic of the market in the education network in the city of Manaus/AM. The implications of this process for education in this municipality are questioned. This is a qualitative research, based on a literature review, survey and analysis of primary documents, from 2013 to 2017. The results indicate that there is an undeniable movement in favor of enabling the expansion of private institutions in the educational sector, which find new niches of economic exploitation, in order to allow the private appropriation of the public good, without, however, effectively generating an improvement in the public school system. The acceptance of this logic promotes changes in the conceptions of public schools, with the incorporation of private institutions in the municipal school system.

Keywords: Public Education. Educational Market. Private Sector. 
Lógica do Mercado na Rede Pública Municipal de Manaus/AM

\section{Introdução}

Entende-se que, para identificar a parceria com o setor privado no cenário da educação pública municipal de Manaus, torna-se relevante a compreensão do mercado educacional desempenhando o papel ideológico de propagadores dos ideais neoliberais na lógica da reestruturação do Estado, tendo a Secretaria Municipal de Educação (SEMED) como mediadora desse processo. Essa estratégia de ação da secretaria se constitui como uma política local, cujo processo é organizado e orquestrado por meio do Projeto de Expansão e Melhoria Educacional da Rede Pública de Manaus (PROEMEM), no período de 2013 a 2017. Sendo palco de debates a forma verticalizada da sua implantação na Secretaria Municipal de Educação (SEMED).

A aplicabilidade e a forma como essa política vem se configurando em cada escola da rede municipal de ensino de Manaus/AM, um processo contraditório, instiga a seguinte indagação: como se deu o processo de implantação do PROEMEM e qual o seu papel na rede pública municipal de Manaus? A partir do ano de 2013, período marcado pela articulação dos assessores do Banco Interamericano de Desenvolvimento (BID) com a gestão da Educação Municipal, deu-se início a elaboração do Projeto de Expansão e Melhoria Educacional da Rede Pública Municipal de Manaus (PROEMEM) com o intuito de solicitar empréstimo ao BID. A partir de então, foi feito um levantamento em todos os departamentos da SEMED, juntamente com a assessoria do BID, cuja exposição de resultados deu-se por meio do primeiro workshop no início do ano letivo de 2014, tendo como objetivo apresentar um diagnóstico das fragilidades da educação pública municipal.

Com a publicação no Diário Oficial do Município (DOM), foi aprovada a Lei municipal ${ }^{\circ}$ 1.921, de 30 de Outubro de 2014 - essa Lei municipal foi revogada pela Lei municipal $n^{\circ}$ 2.230, de 04 de julho de 2017, que reestrutura o PROEMEM para ser executado pelo período de 2017 a 2021 -, que institui no âmbito da SEMED o PROEMEM. O referido projeto foi arquitetado com o objetivo anunciado de expandir a cobertura e melhorar a qualidade da educação infantil e do ensino fundamental, visto que as indicações pelo PROEMEM apresentam em uma de suas ações a implantação dos Programas de Correção de Fluxo. Por indicação do BID, a Secretaria Municipal de Educação, por meio do PROEMEM, iniciou no ano de 2014 o diálogo com o Instituto Ayrton Senna (IAS), instituição sem fins lucrativos que presta assessoria a estados e municípios em assuntos concernentes à Educação, principalmente no tratamento de Programas de Correção de Fluxo, e com a Fundação Itaú Social (FIS), sendo implantado o Programa de Tutoria Educacional (PTE). Ainda nesse mesmo ano, a SEMED contratou o Instituto Áquila, que implantou o Sistema Integrado de Gestão da Educação (GIDE), que visa introduzir uma série de indicadores estratégicos de gestão escolar, responsáveis pelas ações de melhoria, vale ressaltar que esta instituição também foi indicada pelo BID.

Esse processo de parceria com o setor privado (lucrativo ou não lucrativo) tem dado materialidade a uma nova lógica do mercado na organização educacional, que tende a ser fetichizado pelos produtos e pelos serviços negociados com a Secretaria Municipal de Educação (SEMED) em Manaus. A política privatista consolidada pelos contratos e convênios vem acompanhada de um reforço da aparência a fim de diluir as distinções entre o público e 
Lógica do Mercado na Rede Pública Municipal de Manaus/AM

o privado como um processo contrastado, implicando em um movimento privatizante e constituindo a essência do modo de produção capitalista.

\section{A Lógica do Mercado na Educação Municipal}

É possível perceber a ocorrência de fatores relacionados via desregulamentação da legislação na educação nacional e municipal. O enfraquecimento do Estado reduz sua capacidade de organização e de controle de bens e normatiza um quadro legal e institucional para garantir a elevação de empreendimentos de interesse do mercado no interior de escolas públicas. Nesse cenário, as políticas educacionais sofrem diretamente a interferência dessas contradições, devido à centralidade que a educação escolar tem no quadro integrante da política educacional, incluindo diferentes aspectos que parecem estar dentro dessa intencionalidade, ou seja, "[...] de contribuir para o novo papel e funções do Estado, papel esse que deve corresponder às demandas do capital internacional, a partir da lógica do mercado" (MAUÉS, 2006, p. 2).

No entanto, pode-se deduzir que a reforma do Estado e da educação, instaurada a partir dos anos 1990 na América Latina, trouxe "profundas mudanças na organização do trabalho docente, nas suas relações de trabalho" (KRAWCZYK, 2012, p. 348) e, por isso mesmo, a educação adquiriu uma centralidade renovada. Dela se espera, "que prepare as novas gerações para o trabalho no marco de economias modernas e competitivas" (GAJARDO, 2012, p. 333). Segundo Vidigal (2011, p. 9), a década de 1990 foi considerada, na América Latina, a "década da onda neoliberal".

Com essa perspectiva, considera-se que a parceria com o setor privado em educação oculta interesses hegemônicos do grande capital de forma disfarçada e camuflada para legitimar seus projetos e programas, como, por exemplo, o Programa Tutoria Educacional (PTE). Percebe-se, desse modo, que a presença do privado no público apresenta uma crescente sofisticação dos discursos pedagógicos, delineando novos horizontes para o trabalho da docência e funcionando como uma atividade organizativa que, em Manaus, efetiva-se no trabalho dos professores em estágio probatório da educação infantil (creche e pré-escola) e dos anos iniciais do ensino fundamental. Consolida-se e amplia-se, nesse contexto, um grande mercado que "vem sendo disputado por diferentes instituições" (SARTI, 2012, p.329).

Destaca-se, particularmente a partir da década de 1990, o início de um movimento internacional de reforma educacional para enfrentar os desafios de uma "nova ordem econômica mundial" (KRAWCZYK, 2012, p. 347). Essas reformas iniciaram-se com compromissos assumidos pelos governos de diferentes países e pelos organismos internacionais na Conferência Mundial sobre Educação para Todos, realizada em Jomtien, Tailândia, em 1990. A partir desse movimento, a educação passou a ser tema central das reformas políticas e econômicas, sendo "[...] fortemente direcionadas, tanto na definição de suas prioridades quanto de suas estratégias, pelas orientações dos organismos internacionais financiadores" (KRAWCZYK, 2012, p. 347).

É precisamente dentro desse contexto que se deve compreender a parceria com o setor privado e todas as ações voltadas para a sua estimulação e disseminação, evidenciando-se uma nova investida do capital, "[...] de transferir a educação da esfera da política para a esfera do mercado, negando sua condição de direito social e transformando-a em uma possibilidade 
Lógica do Mercado na Rede Pública Municipal de Manaus/AM

de consumo individual" (GENTILI, 1998, p. 19). O processo desencadeador da política educacional municipal, no qual a parceria com o setor privado foi normatizada, permitindo, assim, a institucionalização de interesses privados nas etapas da educação básica municipal, iniciou-se primeiramente com a implantação e execução do PROEMEM. A partir do ano de 2013, seu grupo de trabalho, composto por profissionais da educação pública municipal de Manaus, juntamente com o Banco Interamericano de Desenvolvimento (BID), passou a decidir a parceria com o setor privado como meio de organizar soluções educacionais para a educação infantil e para o ensino fundamental.

Diante disso, cresce, consideravelmente, o envolvimento de fundações e institutos ligados a grupos financeiros que investem fortemente na educação, sob a lógica do mercado educacional. A implicação do setor empresarial nas questões sociais tem crescido substancialmente, sendo assunto que requer maior atenção, reflexão e análise por parte dos educadores e demais profissionais comprometidos com a educação brasileira.

É importante considerar que o processo de implantação das ações do PROEMEM conta com a operação de crédito externo, aderindo ao empréstimo com o BID, cujo objetivo anunciado no projeto é expandir a cobertura e melhorar a qualidade da Educação Básica. Nessa perspectiva de submissão às condicionalidades internacionais, principalmente a partir das políticas de ajuste estrutural e setorial empreendidas por organismos internacionais, como - Banco Mundial (BM), a UNESCO e a Organização de Cooperação e Desenvolvimento Econômico (OCDE), o convênio SEMED - PROEMEM aponta para um só caminho, no qual "[...] o sistema educacional precisa passar por uma reforma visando qualificar melhor as pessoas para enfrentarem um mundo mais competitivo, mais afinado com o mercado" (MAUÉS, 2003, p. 91). Essas exigências apontadas pelos organismos multilaterais atendem a uma nova ordem mundial.

Desse modo, a configuração do PROEMEM no contexto amazônico pode ser analisada considerando também as categorias do público e do privado na educação com aspectos inerentes às relações sociais e à produção da vida material humana. A introdução da lógica do mercado na educação pública municipal nasce da relação contraditória e conflitiva de estruturação dos espaços público e privados no cenário nacional e no âmbito da educação. Esse processo viabiliza a expansão de instituições privadas no setor educacional, encontrando-se novos nichos de exploração econômica que permitem a apropriação privada do bem público, fetichizado por seus produtos e por seus serviços, nas etapas da educação básica do ensino público municipal de Manaus, constituindo uma supervalorização que ultrapassa a realidade desses objetos e a sua relação com o trabalho e o conhecimento humano.

No Brasil, a partir dos anos 1990, as reformas privatizantes permitiram a ampliação de parcerias com o setor privado. Nesse processo, o papel da educação é fundamental para garantir a formação de competências e habilidades estudantis destinadas a atender às demandas do mercado de trabalho. Para Martins (2012, p. 47), os diversos segmentos educacionais, que perpassam da educação infantil ao ensino superior, são conclamados à consolidação de políticas educacionais centradas no treinamento de indivíduos a serviço da organização de mercado. Essa mudança provoca empobrecimento dos fins educacionais, convertidos em meios para promover adaptação passiva dos indivíduos às exigências do capital. A referida autora (2012) afirma que 
Lógica do Mercado na Rede Pública Municipal de Manaus/AM

[...] a educação tem como primeira função firmar as respectivas propriedades ontológicas, o que a coloca com a finalidade de promover condições para a apropriação das objetividades genéricas pelas quais os homens efetivem a atividade objetivadora social e consciente, tendo em vista a máxima universalização e liberdade (MARTINS, 2012, p. 55).

Assim, a educação tem um papel fundamental no processo de construção e transformação da sociedade e no desenvolvimento das propriedades essencialmente humanas, com a clareza de que a verdadeira educação é a transformação histórica do ser em direção a um ideal humano superior, tendo neste ideal a "[...] abolição das condições e instituições que alienam o trabalho e o trabalhador, para que ele possa objetivar sua atividade vital de modo consciente, social, universal e livre" (MARTINS, 2012, p. 56).

Krawczyk (2000, p. 6) chama a atenção para observar as reformas educacionais dos anos 1990, que tiveram um caráter homogeneizante tanto na leitura das realidades nacionais quanto nas suas propostas, pretendendo impor uma padronização de ações para a região e anulando assim a possibilidade de definir políticas que tenham como ponto de partida a sua realidade específica. Ou seja, diante do caráter regressivo das relações sociais que procuram impor o novo estágio do desenvolvimento capitalista, cabe-nos desentranhar, nos novos modelos de organização socioeconômica, os espaços de contradição que permitam a construção social de um projeto educacional mais democrático e socialmente justo.

Nesse período, intensificou-se um movimento internacional de adequação dos denominados sistemas educacionais dos países capitalistas, vinculado ao amplo processo de reestruturação da produção da vida material e social. Com isso, redefiniram-se o conteúdo e a forma de estruturação dos sistemas educacionais e as leis de mercado passaram a ser usadas como referência para as políticas públicas elaboradas e implementadas nesses países. A reforma educacional dos anos 1990 "[...] é um elemento importante da mudança do caráter regulador do Estado e contém tensões e lutas que emergem dessas mudanças" (KRAWCZYK, 2000, p. 5). Durante o período reformista dos anos 1990, as lideranças econômicas e governamentais implantaram a lógica gerencial que corresponde à necessidade de reduzir custos e aumentar a qualidade dos serviços, perpassando pelos valores de eficiência, qualidade e cultura gerencial com maior participação dos agentes privados (BRASIL, 1995). Esse receituário, como se sabe, faz parte do movimento para reformular a organização burocrática do Estado e para responder e acompanhar o processo de internacionalização financeira do capital.

Nesse contexto, definiu-se a proposta de transferir para os estados e municípios, no Brasil, as ações de caráter local, entre outras, fazendo com que os serviços sociais se tornassem mais viáveis e competitivos nessas localidades. Os diagnósticos e o quadro teórico apresentados no Plano Diretor serviram de base para as propostas da Emenda Constitucional que o Poder Executivo apresentou ao Congresso Nacional para as reformas nas áreas administrativa e previdenciária (BRASIL, 1995, p. 7). Segundo consta no Plano Diretor (BRASIL, 1995), a crise do Estado definia-se como:

1) crise fiscal, caracterizada pela crescente perda do crédito por parte do Estado e pela poupança pública que se torna negativa; 2) o esgotamento da estratégia estatizante de intervenção do Estado, a qual se reveste de várias formas: O Estado do bem-estar social nos países desenvolvidos, a estratégia de substituição de importações no terceiro mundo, e 
Lógica do Mercado na Rede Pública Municipal de Manaus/AM

o estatismo nos países comunistas; e 3 ) a superação da forma de administrar o Estado, isto é, a superação da administração pública burocrática (BRASIL, 1995, p. 11).

Esse diagnóstico de crise fiscal, segundo Peroni (2015, p. 14), esboça uma premissa das justificativas utilizadas para reformar o Estado. Contudo, essa crise é apenas uma das várias facetas da crise do capital. Portanto, toda a estratégia de reforma do Estado, desmantela-o no que se refere às políticas sociais (PERONI, 2015, p. 14).

Na proposta de reforma do Estado, a ideia que prevalece é, além da propriedade pública e da propriedade privada, a de que existe a propriedade pública não-estatal, caso em que se enquadraria o setor das atividades não-exclusivas do Estado, como saúde e educação. E, como propriedade pública não-estatal, a educação contaria com a participação de conselhos de administração compostos pelos segmentos envolvidos, favorecendo a parceria entre o Estado e a sociedade (BRASIL, 1995, p. 43).

Nesse contexto, as decisões sobre as políticas sociais privilegiam ideias designadas a convocar a participação da sociedade civil na efetivação de ações voltadas às denominadas populações carentes. Essas ações marcam a entrada ativa de representantes da sociedade civil com suas organizações, como as fundações e as Organizações Não Governamentais (ONGs). Esses movimentos articulam-se numa nova configuração da mundialização do capital, essa expressão corresponde ao termo inglês globalização, que traduz a capacidade estratégica de todo grande grupo oligopolista voltado para a produção manufatureira ou para as principais atividades de serviços, de adotar, por conta própria, um enfoque e conduta globais. Na análise de Chesnais (1996, p. 299), ter como foco principal a hegemonia do capital financeiro na mundialização dos dias atuais mostra que:

[...] o papel desempenhado pela internacionalização do capital no processo de desregulamentação cumulativa dos mecanismos associados à regulação fordista, adquire importância ainda maior, quando se leva em conta a internacionalização do capital monetário ao mesmo título do que a do capital produtivo, isto é, como expressões distintas, mas interligadas, de um movimento único de liberação do capital de todas as instituições que enquadravam e 'regulavam' suas operações (CHESNAIS, 1996, p. 299).

Os elementos que se manifestam nesse processo são dados que permitem a compreensão da configuração de um novo conjunto de relações econômicas e políticas, evidenciando o caráter excludente e destrutivo da lógica do capital, por certo, não dissociadas de um quadro amplo de modificações econômicas, políticas e sociais, de alcance mundial.

A partir dos anos 1980, muitas saídas encontradas pelos governos para resolver essas questões essenciais para a preservação da vida humana passaram a ser adotadas, com um grau de abrangência e operacionalidade nos marcos dos programas de ajuste de cunho neoliberal, em que a lógica mercantilista adquiriu função de destaque nas formulações de políticas sociais. O debate mundial que se constituiu sobre o lugar e a natureza das políticas econômicas e das políticas públicas sociais está inserido nos parâmetros de correção da ordem socioeconômica constituída para que sejam permanecidas e conservadas "[...] as determinações estruturais fundamentais da sociedade como um todo, em conformidade com as exigências inalteráveis da lógica global de um determinado sistema de reprodução" (MÉSZÁROS, 2008, p. 25 grifos do autor).

Segundo Oliveira (2009), no Brasil, o processo de desenvolvimento de um setor empresarial na educação é antigo, remontando, pelo menos, ao período da ditadura militar. 
Lógica do Mercado na Rede Pública Municipal de Manaus/AM

Não obstante, isso era dissimulado, pois a legislação proibia que as instituições de ensino dessem lucro. Somente com a promulgação da Constituição de 1988 é que se explicitou a possibilidade da existência de escolas com fins lucrativos. A posterior regulamentação desse dispositivo na Lei de Diretrizes e Bases e na legislação complementar acelerou o seu crescimento (OLIVEIRA, 2009, p. 741). Tal processo de recolocação da educação como um serviço sujeito às leis de mercado permite a transformação da educação em objeto do interesse do grande capital, ocasionando uma crescente comercialização do setor.

Faz-se necessário entender o fenômeno de parceria com o setor privado nos espaços das lutas de classes com seus sujeitos histórico-sociais, pois é no interior desse movimento que se manifestam, historicamente, tanto nas relações de dominação ou de dependência quanto nas relações de resistência. "Toda história política tem sido uma história de lutas de classes, de lutas entre classes dominantes, nos diferentes estágios do desenvolvimento social" (MARX; ENGELS, 2007, p. 46). Nesse sentido, considerando a diversidade dos fios com os quais se tece a história, uma possível maneira de abordar esse fenômeno de parceria com o setor privado consiste em traçar o processo conflituoso e contraditório que caracteriza o desenvolvimento histórico do capitalismo, compreendendo a abrangência desse processo, ao mesmo tempo conservador e transformador, constituindo a essência do modo de produção capitalista. Assim, "[...] o modo de produção da vida material condiciona o processo de vida social, política e intelectual” (MARX, 2008, p. 47).

A educação tornou-se um dos temas fundamentais das discussões e decisões sobre as políticas governamentais realizadas a partir do início do século XXI. No entanto, o ponto central no debate envolvendo a estruturação da educação escolar para o povo brasileiro apresenta importantes possibilidades de compreender a precária escola pública brasileira, que, por sua vez, não ocorreu apenas entre projetos formuladores e conduzidos a partir do Estado e de outras instituições consolidadas (como a Igreja e as associações filantrópicas), mas se manifesta no campo da construção, tramitação e aprovação de projetos educacionais de natureza pública e privada, que nem sempre se apresentam como projetos de ação nitidamente delineados.

É importante destacar que a estruturação da educação pública brasileira se deu no auge da consolidação do capitalismo como modo de produção, contando com a crescente participação da iniciativa privada, especialmente a empresarial, na composição econômica, política e social do País. O setor privado empresarial, nesse âmbito, desempenhou influência sobre as políticas do Estado, atuando em defesa dos interesses da propriedade privada e não de uma revolução industrial em conjunto com uma transformação social e educacional.

\section{A Parceria com o Setor Privado na Rede Pública Municipal}

Discute-se aqui o processo de implantação e execução do PROEMEM e seu papel na rede pública municipal de ensino de Manaus, questões referentes à materialidade do público e do privado na política neoliberal para a educação básica, bem como seus desdobramentos, no presente cenário da educação pública brasileira. São apresentadas as referências teóricas que permitem delinear o percurso investigativo, de tal modo que desvele as políticas públicas de inserção do PROEMEM. Assim, na análise de Peroni (2015, p. 14), "[...] quando as instituições privadas, por meio das parcerias, pretendem qualificar o serviço público, a proposta de qualidade não é neutra: são concepções de sociedade em disputa". 
Lógica do Mercado na Rede Pública Municipal de Manaus/AM

Destaca-se, no início do século XXI, o movimento Todos pela Educação, constituído por representantes da sociedade civil, educadores, empresários, organizações sociais e gestores públicos de Educação com intensa influência nos meios de comunicação. O documento do ano de 2006 refletiu o anseio desse grupo de chegar em 2022 festejando o bicentenário da Independência num país com escolas boas, com oportunidades iguais para todos e livre do analfabetismo (TODOS PELA EDUCAÇÃO, 2006-2009, p. 15). Configurando essa discussão de classe do Movimento Todos pela Educação, os empresários dão a direção da política educacional e promovem o consenso em torno de cinco metas propostas como objetivos a serem alcançados até 2022: Meta 1 - Toda criança e jovem de 4 a 17 anos na escola; Meta 2 - Toda criança plenamente alfabetizada até os 8 anos; Meta 3 - Todo aluno com aprendizado adequado ao seu ano; Meta 4 - Todo jovem de 19 anos com Ensino Médio concluído e a Meta 5 - Investimento em Educação ampliado e bem gerido - Aperfeiçoamento da gestão e da governança da Educação. A partir dessas metas, o grupo propõe a divulgação e o monitoramento da educação no País e passa a intervir nos parâmetros do que considera a qualidade desse intrincado processo de relações empresariais que toma conta de uma fatia do mercado educacional, justificado pelos empresários em torno de um discurso comum de "qualidade da educação". Esse assunto será estudado no próximo capítulo, em que se mencionam as denominadas parcerias com as empresas educacionais privadas.

A educação escolar é entendida como uma dimensão importante no campo político, contudo, ela não se configura só como forma de garantir o acesso das populações à educação básica, na busca por vagas no mercado de trabalho, ela é uma estratégia amplamente utilizada para qualificar a participação dos países capitalistas no processo produtivo internacionalizado. E, nesse aspecto, as formulações e políticas educacionais realizadas no âmbito das agências internacionais deram as diretrizes de como os países devem proceder com seus sistemas educacionais para garantir a satisfação das necessidades básicas de aprendizagem.

Diante desse quadro, a lógica do mundo privado, com sua ênfase no mercado, no individualismo e no consumismo, instaura-se no interior do espaço público escolar. Assim,

[...] parece-me de fundamental importância investigar a relação público e privado do ponto de vista das tentativas de consolidação em novos moldes, no interior da gestão das escolas públicas, de um referencial onde predomina a visão de que o paradigma da modernidade é a empresa privada e seu ideal de excelência e competividade. Para além das lutas que se trataram nas duas últimas décadas em torno do controle público e do destino das verbas estatais para a educação, os anos 90 trazem esta inflexão em direção à emergência da lógica privada na administração do ensino (LEÃO, 2003, p. 118).

Desse modo, a parceria com o setor privado na educação municipal, conforme se realiza no município de Manaus e em muitos municípios brasileiros, é mais uma face dessa relação contraditória entre escola pública e instituições privadas, revelando-se numa fase mais ampliada desses processos de privatização da educação. Com essa prerrogativa e na obtenção de sua autonomia, o município de Manaus implantou na Secretaria Municipal de Educação, em 30 de outubro de 2014, o Projeto de Expansão e Melhoria Educacional da Rede Pública Municipal de Manaus (PROEMEM), que conta com financiamento global de US\$104.000.000,00 (cento e quatro milhões de dólares norte-americanos). Destes, US\$ $52.000 .000,00$ (cinquenta e dois milhões de dólares) são oriundos de uma operação de crédito com o Banco Interamericano de Desenvolvimento (BID) e, os outros 52 milhões de dólares, 
da contrapartida do orçamento da Secretaria Municipal de Educação (SEMED) Manaus e repasses do Ministério da Educação (MEC).

Os contratos de empréstimos e de garantia foram firmados em 14 de julho de 2017, tendo sido a República Federativa do Brasil representada no ato pela Procuradora da Fazenda Nacional, que esta subscreve, no uso da competência que Ihe foi conferida mediante a Portaria PGFN n 713, de 04 de julho de 2017, publicada no Diário Oficial da União (DOU), em 06 de julho de 2017. O PROEMEM, em seu objetivo geral anuncia que pretende ampliar a cobertura e melhorar a qualidade da educação infantil e ensino fundamental da rede municipal, partindo da premissa de inclusão para quatro ações componentes.

Quadro 1 - Custos Financeiros do PROEMEM

\begin{tabular}{|c|l|c|}
\hline AÇÃo & \multicolumn{1}{|c|}{ OBJETIVOS } & TOTAL \\
\hline $\begin{array}{c}\text { COMPONENTE 1: Expansão } \\
\text { e Melhoria da Cobertura da } \\
\text { Educação Infantil e Ensino } \\
\text { Fundamental }\end{array}$ & $\begin{array}{l}\text { Expandir o acesso à educação básica, compreendendo a } \\
\text { educação infantil o o ensino fundamental, por intermédio da } \\
\text { construção de unidades de ensino de educação básica. }\end{array}$ & U\$ 63.380.000,00 \\
\hline $\begin{array}{c}\text { COMPONENTE 2: Melhoria } \\
\text { da Qualidade da Educação }\end{array}$ & $\begin{array}{l}\text { Aprimorar o rendimento e o desempenho escolar dos } \\
\text { alunos da rede pública municipal de ensino. }\end{array}$ & U\$ 26.260.000,00 \\
\hline $\begin{array}{c}\text { COMPONENTE 3: Gestão, } \\
\text { Monitoramento e Avaliação }\end{array}$ & $\begin{array}{l}\text { Fortalecer a educação básica por meio de projetos } \\
\text { pedagógicos e reforço escolar, aceleração da } \\
\text { aprendizagem, seleção formação de professores } \\
\text { formadores, gestão, monitoramento e avaliação do } \\
\text { desempenho escolar dos alunos da rede pública municipal } \\
\text { de ensino. }\end{array}$ & U\$ 8.030.000,00 \\
\hline $\begin{array}{c}\text { COMPONENTE 4: } \\
\text { Administração do Projeto }\end{array}$ & $\begin{array}{l}\text { Robustecer a capacidade institucional da SEMED para } \\
\text { gerenciar, monitorar e avaliar o sistema educativo } \\
\text { municipal. }\end{array}$ & U\$ 6.330.000,00 \\
\hline TOTAL & \multicolumn{1}{|c|}{} \\
\hline
\end{tabular}

Fonte: MANAUS. Secretaria Municipal de Educação (2013). Disponível em: http://www.iadb.org/en/projects/project-descriptiontitle,1303.html?id=BR-L1392. Acesso em: 20 jun. 2015.

O Quadro 1 mostra os desembolsos previstos para a execução das ações do PROEMEM para o período de 2017 a 2021. Os parâmetros de custos financeiros foram disponibilizados pelo BID. Nesse quadro pode-se verificar esses fluxos em dólares correntes, calculados com base em uma taxa de câmbio de 3,09930. O custo total em valores correntes é de US\$104.000.000,0045. Como se pode notar pelo referido quadro, os custos estão divididos em 4 componentes: Componente 1 - tem como ação expandir a cobertura e melhorar a educação infantil e ensino fundamental, constituem a maior parte dos custos do projeto, que corresponde a U\$63.380.000,00, que anuncia como objetivo ampliar a cobertura da educação infantil e ensino fundamental e a expansão e melhoria da infraestrutura escolar. Esse componente deve financiar: a construção de Centros de Educação Infantil (CMEI) e creches; construção de Escolas Municipais de Ensino Fundamental (EMEF) e aquisição de bens e materiais duráveis para equipar as unidades.

O Componente 2 - tem como ação melhorar a qualidade da educação. Compõe no total de despesas U\$ 26.260.000,00. Esse componente anuncia como objetivo melhorar o desempenho dos alunos da rede da educação infantil e ensino fundamental, devendo financiar: a concepção e implementação de programas de aceleração da aprendizagem e reforço escolar com o apoio do Instituto Airton Sena (IAS); a reformulação de concursos para a seleção de novos professores, bem como a revisão do período de estágio probatório, 
Lógica do Mercado na Rede Pública Municipal de Manaus/AM

acompanhando professores contratados por meio de um sistema de coaching46; a revisão do processo de seleção de formadores da SEMED, responsáveis pela formação de professores e gestores da rede, com formação em nível de mestrado profissional e treinamento; os projetos educacionais para a melhoria do desempenho educacional e gestão escolar, selecionados criteriosamente para a obtenção de um fundo de investimento; e o desenvolvimento de matrizes curriculares articuladas para facilitar as transições entre níveis de ensino.

O Componente 3 - tem como ação gestão, monitoramento e avaliação. Compõem U\$ 8.030.000,00 no total de despesas previstas para esse componente. Anuncia como objetivo reforçar a capacidade de gestão da rede de ensino da SEMED. Isso levaria a atividades relativas à: implementação de novos processos de seleção e avaliação de professores e administradores; implementação do Sistema de Avaliação de Desempenho Educacional de Manaus (SADEM), que terá três componentes: um de desempenho escolar (ADE), com base nos resultados do Sistema Estadual de Avaliação do Estado do Amazonas (SADEAM); outro com índice de Avaliação Gestão Escolar (AGE) e o desenvolvimento e implementação de um sistema de monitoramento da qualidade da educação infantil; o desenvolvimento de uma estratégia e de relações com o setor privado e a sociedade civil comum; e a elaboração e implementação de avaliações de processos e impactos gerados pelo Projeto.

E o Componente 4 - tem como ação a gestão do Projeto. Compõem o total de despesas previstas de U\$6.330.000,00. A fim de proporcionar a execução do Projeto, será realizada a criação da Unidade de Gerenciamento de Projetos (UGP); a aquisição de bens para o seu funcionamento e a prestação de apoio à gestão e auditoria externa.

Para a execução da ação do Componente 2, a SEMED firma convênio com a Fundação Itaú Social (FIS), por meio do Programa de Tutoria Educacional (PTE), que, de acordo com o documento Guia de Tutoria de Área, define a tutoria como uma metodologia de formação em serviço, realizada no cotidiano da escola, pelo tutor, com o tutorado (professor), para desencadear o processo de aprendizagem, buscando agregar novos conhecimentos, de caráter prático, e modelar com o objetivo de melhorar os resultados de aprendizagem dos alunos. Ainda nesse documento, apresentam-se os princípios da tutoria, cuja rotina de trabalho do tutor se pauta em alguns princípios tais como: aprendizagem na prática, parceria, customização, protocolos combinados, intencionalidade e transparência, foco na aprendizagem dos alunos.

Portanto, implanta-se o Programa de Tutoria Educacional (PTE) da Fundação Itaú Social (FIS), conforme o termo de convênio de $n^{\circ} 12$ de 2015, entre a SEMED e a Fundação Itaú Social na forma do Plano de Trabalho, para a definição de estratégias e análises à implementação de soluções educacionais para o enfrentamento das questões relativas à educação infantil e ao ensino fundamental na rede pública municipal de ensino. Essa Secretaria tem divulgado para os profissionais da educação infantil e ensino fundamental a crença de que, esse produto e serviço adquirido, resultados da ação humana e incorporados nos produtos e serviços em alguns estados brasileiros, são capazes de promover, por si só, transformações substanciais na vida das crianças e jovens do município de Manaus, elevando a qualidade da educação. A justificativa, de acordo com o documento Plano de Trabalho para esse convênio com a FIS, é o financiamento que a SEMED capitaneou com o Banco Interamericano de Desenvolvimento (BID), para a promoção de ações que visam à melhoria 
Lógica do Mercado na Rede Pública Municipal de Manaus/AM

do processo educacional do município, sendo que essas negociações junto ao BID resultaram na implementação do PROEMEM.

Conforme verifica-se que o empréstimo de US $\$ 52.000 .000,00$ (cinquenta e dois milhões de dólares americanos) que o Município de Manaus tomou junto ao BID é amparado pelo programa de meta educacional do Município de Manaus, atuando alinhado às Políticas Públicas para os setores, tanto Nacional quanto Estadual, para elevar os níveis de excelência na educação, assim, espera-se melhorar o desempenho acadêmico dos alunos medido pela Prova Brasil. Os recursos do empréstimo serão aplicados na expansão da infraestrutura educacional da rede de ensino municipal, na melhoria da qualidade da educação, assim como na gestão, monitoramento e avaliação do ensino.

Esta justificativa, apresentada no documento do PROEMEM, o financiamento externo do BID, consubstancia-se em reformas educacionais para o município de Manaus. Sem se dar conta disso, essa gestão da educação municipal endossa propostas pedagógicas que "expressam a concepção liberal burguesa de sociedade e de indivíduo" (FACCl, 2012, p. 101). É preciso estar vigilante às maneiras, por vezes sutis, pelas quais as ideologias liberal e neoliberal estão presentes em determinadas orientações dadas às políticas educacionais, uma vez que expressam a materialização dos motivos financeiros e institucionais, e das razões econômicas e ideológicas que compõem as relações de poder e se beneficiam nesse processo imposto pelo ritmo do capital financeiro internacional. Nessa perspectiva, o discurso apresentado por agências financeiras multilaterais soa como se essas reformas educacionais fossem suficientes para o homem realizar a apropriação do conhecimento e provocar mudanças na sua prática social (FACCI, 2012, p. 101).

As condicionalidades requeridas pelas agências financeiras multilaterais se sustentam em um diagnóstico macroeconômico mundial e a sua concepção central comporta os mesmos pressupostos norteadores político, econômico e ideológico dessas agências. Articulado ao diagnóstico e ao receituário macroeconômico proposto, estão as agências financeiras multilaterais. Nesse cenário, os empréstimos são realizados pelas agências financeiras multilaterais e seguem um processo de operacionalização, de implementação e de condicionalidades políticas e financeiras sistemáticas. Por conseguinte, envoltos nesse processo, os ajustes estruturais e setoriais permitem uma noção genérica sobre uma parte desse artifício de acumulação de capital, ao verificar o volume e o movimento financeiro gerado pelos mesmos e permitem ainda observar a realização de reformas que constituem o engendramento desse processo em âmbitos financeiros e institucionais, econômicos e ideológicos.

\section{Conclusões}

Este trabalho procurou desvelar a ilusória parceria com o setor privado no cenário da educação pública municipal de Manaus, materializado na implantação do PROEMEM na SEMED. Nesse sentido, o referido projeto coaduna-se às demandas neoliberais. Essas interferências têm sua origem e legitimação na busca da consolidação de princípios mercadológicos no esforço para se garantir processos de privatização educacionais.

A conjuntura é marcada pela globalização econômica e pelos organismos internacionais no processo da reforma educacional, que desempenham papel ideológico de propagadores do neoliberalismo social. Diante disso, cresce consideravelmente o envolvimento de 
Lógica do Mercado na Rede Pública Municipal de Manaus/AM

fundações e institutos ligados a grupos financeiros investindo fortemente no mercado educacional aberto.

Assim, as parcerias com o setor privado fazem parte do cenário internacional e nacional desde as últimas décadas do século $\mathrm{XX}$, em que se fortaleceram as políticas e reformas neoliberais no contexto da globalização da economia. Verifica-se que esse movimento não se limita ao processo político-econômico do neoliberalismo e da globalização, pois, no Brasil, foi se consolidando historicamente e se ampliou a partir dos anos 1990, momento em que a sociedade civil foi conclamada a participar ativamente de novas formas de gestão da administração pública em sociedades do tipo democráticas. Organizadas em ONGs, associações de classes, empresas privadas, entre outras, a sociedade civil tem atuado em instituições do Estado, em ações envolvendo programas políticos, socioculturais e educativos que são propostos no País.

Por essa razão, problematiza-se, neste estudo, a materialidade do PROEMEM na rede pública municipal de ensino de Manaus/AM, evidenciando a lógica do mercado no contexto da parceria com o setor privado, nas etapas da educação básica do ensino público municipal. Verificou-se que tem se materializado a lógica do mercado na organização e no funcionamento das etapas da educação básica do ensino público municipal, advertindo-se sobre a importância dada às questões essenciais, como a relação entre Estado e educação, perante o fato de que as políticas e diretrizes, construídas para garantir as condições materiais de sustentação do atendimento escolar público, estão se dando na esfera dos interesses do mercado. A educação está sendo concebida como mercadoria.

\section{Referências}

BRASIL. Ministério da Administração e Reforma do Estado (Mare). Plano Diretor da Reforma do Aparelho do Estado no Brasil. Brasília, DF, 1995. Disponível em: http://www.biblioteca .presidencia.gov.br/publicacoes-oficiais/catalogo/fhc/plano-diretor-da-reforma-do-aparelhodo-estado-1995.pdf. Acesso em: 24 set. 2017.

BRASIL. TODOS PELA EDUCAÇÃO (2006-2009). Brasília, 2017. Disponível em: https://www.todospelaeducacao.org.br. Acesso em: 23 abr. 2017.

CHESNAIS, François. A mundialização do capital. São Paulo: Xamã, 1996.

FACCI, Marilda Gonçalves Dias. Teorias Educacionais e Teorias Psicológicas: em busca de uma psicologia marxista da educação. In: DUARTE, Newton (Org). Crítica ao fetichismo da individualidade. 2. ed. Campinas: Autores Associados, 2012. p. 87-103.

GAJARDO, Marcela. Reformas educativas na América latina: balanço de uma década. In: BROOKE, Nigel (Org.). Marcos histórico na formação da educação. Belo Horizonte: Fino Traço, 2012. p. 333-346.

GENTILI, Pablo. A falsificação do consenso: simulacro e imposição na reforma educacional do neoliberalismo. Petrópolis: Vozes, 1998.

KRAWCZYK, Nora. A construção social das políticas educacionais no Brasil e na América Latina. In: KRAWCZYK, Nora; CAMPOS, Maria Malta; HADDAD, Sergio (Org.). 0 cenário educacional latino-americano no limiar do século XXI: reformas em debate. Campinas: Autores Associados, 2000. p. 1-11. 
Lógica do Mercado na Rede Pública Municipal de Manaus/AM

KRAWCZYK, Nora. A construção social das políticas educacionais no Brasil e na América Latina. In: BROOKE, Nigel (Org.). Marcos históricos na formação da educação. Belo Horizonte: Fino Traço, 2012. p. 347-349.

LEÃO, Geraldo Magela Pereira. "Novas" estratégias da gestão privada da educação pública. In: OLIVEIRA, Dalila Andrade; DUARTE, Marisa Ribeiro Teixeira. (Org.). Política e Trabalho na escola: administração dos sistemas públicos de educação básica. Belo Horizonte: Autêntica, 2003.

MANAUS. Secretaria Municipal de Educação. Carta Consulta Programa de Expansão e Melhoria Educacional da Rede Pública Municipal de Manaus-PROEMEM. Manaus, 2013. Disponível em: http://www.iadb.org/en/projects/project-description-title,1303.html?id=BRL1392. Acesso em: 20 jun. 2015.

MANAUS. Lei Municipal n 1.921, de 30 de Outubro de 2014. Institui, no âmbito da Secretaria Municipal de Educação - SEMED, o Projeto de Expansão e Melhoria Educacional da Rede Pública Municipal de Manaus - PROEMEM, e estabelece outras providências. Diário Oficial do Município de Manaus, Manaus, AM, 30 de outubro de 2014. Disponível em: http://dom.Manaus.am.gov.br/pdf/2014/outubro/DOM\%203525\%2030.10.2014\%20CAD\%20 1.pdf/. Acesso em: 28 mar. 2016.

MANAUS. Lei Municipal $n^{\circ} 2.230$, de 04 de julho de 2017. Reestrutura o Projeto de Expansão e Melhoria Educacional da Rede Pública Municipal de Manaus (Proemem) e estabelece outras providências. Diário Oficial do Município de Manaus, Manaus, AM, 04 de julho de 2017. Disponível em: http://dom.manaus.am.gov.br/pdf/2017/julho/DOM\%204161\%2007.07.2017 \%20CAD\%201.pdf. Acesso em: 10 jul. 2017.

MARTINS, Lígia Márcia. Da formação humana em Marx à crítica da pedagogia das competências. In: DUARTE, Newton (Org.). Crítica ao fetichismo da individualidade. 2. ed. Campinas: Autores Associados, 2012. p. 47-64.

MARX, Karl; ENGELS. A ideologia alemã. 3. ed. São Paulo: Martins Fontes, 2007.

MARX, Karl. Contribuição à crítica da economia política. 2. ed. São Paulo: Expressão Popular, 2008.

MAUÉS, Olgaíses Cabral. Reformas internacionais da educação e formação de professores. Cadernos de Pesquisa, São Paulo, n. 118, p. 89-117, mar. 2003.

MAUÉS, Olgaíses Cabral. A reforma da educação superior e o trabalho docente. Rio de Janeiro: UERJ, 2006.

MÉSZÁROS, István. A educação para além do capital. São Paulo: Boitempo, 2008.

OLIVEIRA, Romualdo Portela de. A transformação da educação em mercadoria no Brasil. Educação \& Sociedade, Campinas, v. 30, n. 108, p. 739-760, out. 2009. Disponível em http://www.cedes.unicamp.br. Acesso em: 01 set. 2017.

PERONI, Vera. Diálogos sobre as redefinições no papel do Estado e nas fronteiras entre o público e o privado na educação. São Leopoldo: Editora Oikos, 2015.

SARTI, Flavia Medeiros. O triângulo da formação docente: seus jogadores e configurações. Educação e Pesquisa, São Paulo, v. 38, n. 2, p. 323-338, abr./jun. 2012. Disponível em: 
Lógica do Mercado na Rede Pública Municipal de Manaus/AM

http://www.periodicos.rc.biblioteca.unesp.br/index.php/educacao/article/view/10286. Acesso em: 07 jan. 2017.

VIDIGAL, Carlos Eduardo. A nova ordem mundial. In: OLIVEIRA, Henrique Altemani; LESSA, Antônio Carlos (Org.). Política internacional contemporânea: mundo em transformação. São Paulo: Saraiva, 2011. p. 1-16.

Rudervania da Silva Lima Aranha é doutoranda do Programa de Pós-graduação em Educação da Universidade Federal do Amazonas (PPGE/UFAM), Integrante do Grupo de Pesquisa em Políticas Públicas - PPGE e integrante do grupo de pesquisa em políticas públicas (GPPE).

ORCID: http://orcid.org/0000-0002-7111-0720

E-mail: rudervania.aranha@gmail.com

Selma Suely Baçal de Oliveira é graduada em Pedagogia pela Universidade Federal do Amazonas (1991), com Mestrado (1998) e Doutorado (2002) em Educação, ambos pela Universidade de São Paulo. É professora (Associado 4) da Universidade Federal do Amazonas com atuação no Curso de Licenciatura Plena em Pedagogia e no Programa de Pós-Graduação em Educação da UFAM, onde orienta discentes de Doutorado e Mestrado. Desenvolve trabalhos no campo das Políticas Públicas e Educação, sendo líder do Grupo de Estudos e Pesquisas sobre Políticas Públicas e Educação na UFAM.

ORCID: http://orcid.org/0000-0001-6765-4568

E-mail: selmabacal@ufam.edu.br 


\section{Editores do volume 11}

Márcia Aparecida Jacomini - Universidade Federal de São Paulo, Brasil

José Marcelino de Rezende Pinto - Universidade de São Paulo, Brasil

\section{Comitê Editorial}

Nalú Farenzena - Universidade Federal do Rio Grande do Sul, Brasil

Juca Gil - Universidade Federal do Rio Grande do Sul, Brasil

Theresa Adrião - Universidade Estadual de Campinas, Brasil

Ângelo Ricardo de Souza - Universidade Federal do Paraná, Brasil

\section{Conselho Editorial}

\section{Alejandro Morduchowicz}

Universidad Pedagógica, Provincia de Buenos Aires, Argentina

Andréa Barbosa Gouveia

Universidade Federal do Paraná, Brasil

Fernanda Saforcada

Universidade de Buenos Aires, Argentina

Jacques Velloso

Universidade de Brasília, Brasil

João Monlevade

Senado Federal, Brasil

Jorge Abrahão de Castro

Instituto de Pesquisa Econômica Aplicada / IPEA, Brasil

Lisete Regina Gomes Arelaro

Universidade de São Paulo, Brasil

Luis Carlos Sales

Universidade Federal do Piauí, Brasil

Luiz de Sousa Junior

Universidade Federal da Paraíba, Brasil

Luiz Fernandes Dourado

Universidade Federal de Goiás, Brasil

Magna França

Universidade Federal do Rio Grande do Norte, Brasil

Marcos Edgar Bassi

Universidade Federal de Santa Catarina, Brasil

Maria Angélica Pedra Minhoto

Universidade Federal de São Paulo, Brasil

Maria Beatriz Luce

Universidade Federal do Rio Grande do Sul, Brasil

Maria Dilnéia Espíndola Fernandes

Universidade Federal de Mato Grosso do Sul, Brasil

Nelson Cardoso do Amaral

Universidade Federal de Goiás, Brasil

Nicholas Davies

Universidade Federal Fluminense, Brasil

Robert E. Verhine

Universidade Federal da Bahia, Brasil

Romualdo Portela de Oliveira

Universidade de São Paulo, Brasil

Rosana Gemaque Rolim

Universidade Federal do Pará, Brasil

Rubens Barbosa de Camargo

Universidade de São Paulo, Brasil

Theresa Adrião

Universidade Estadual de Campinas, Brasil

Tristan McCowan

University of London, Reino Unido

Vera Jacob

Universidade Federal do Pará, Brasil

Vera Peroni

Universidade Federal do Rio Grande do Sul, Brasil

Vitor Henrique Paro

Universidade de São Paulo, Brasil

\section{Equipe editorial}

Apoio ao Comitê Editorial: Caio Cabral da Silva

Diagramação, Revisão de português e normalização: Edson Leonel de Oliveira

Revisão de inglês: Sabrina Ferreira

Fineduca - Revista de Financiamento da Educação

Associação Nacional de Pesquisa em

Financiamento da Educação

e-mail: revista.fineduca@gmail.com | site: http://seer.ufrgs.br/fineduca 